\title{
Prostitución en contextos de conflicto armado en Colombia*
}

\author{
DOI: https://doi.org/10.18046/recs.i31.3508 \\ Prostitution in Armed Conflict Contexts in Colombia \\ Gabriel Gallego-Montes ${ }^{* *}$ \\ Universidad de Caldas (Manizales, Colombia)
}

\begin{abstract}
* El presente documento es un artículo de investigación científica producto del proyecto "Sexualidades e identidades de género disidentes en el marco del conflicto armado colombiano: 1985-2015, un aporte a la memoria y la construcción de paz", financiado por la Universidad de Caldas y la Universidad Nacional de Colombia, sede Manizales. El estudio se adelantó desde julio de 2016 hasta febrero de 2019. Artículo de investigación recibido el 07.04.2019 y aceptado el 17.01.2020.

** Doctor en Estudios de Población por El Colegio de México (México). Magíster en Planeación y Administración del Desarrollo Regional de la Universidad de los Andes (Colombia). Profesional en Desarrollo Familiar de la Universidad de Caldas (Colombia). Profesor asociado del Departamento de Estudios de Familia de la Universidad de Caldas (Colombia). Correo electrónico: gabriel.gallego@ucaldas.edu.co ORCID: http://orcid.org/oooo-ooo2-9079-0645
\end{abstract}




\section{Cómo citar/How to cite}

Gallego-Montes, Gabriel (2020). Prostitución en contextos de conflicto armado en Colombia. Revista CS, 31, 413-437. https://doi.org/10.18046/recs.i31.3508 


\section{Resumen}

El artículo presenta dos casos de victimización de trabajadoras sexuales en el marco del conflicto armado en los municipios de Manzanares y Samaná, Caldas. En términos metodológicos, la investigación se planteó desde una perspectiva cualitativa, la cual establece una centralidad del testimonio y el relato de los sobrevivientes y testigos de los hechos que posibilita la reconstrucción en clave de memoria histórica. Los hallazgos permiten inferir que las zonas de tolerancia, los bares y las cantinas donde se ejerce la prostitución configuran, en los pequeños pueblos de montaña, lugares de frontera, liminares entre lo urbano y lo rural, zonas rojas y bombas de tiempo, en cuanto constituyen focos de circulación de información y regulación social por parte de los ejércitos regulares e irregulares y los hace el blanco perfecto para las acciones de limpieza social y desplazamiento forzado basado en el estigma y el señalamiento de cooperación a ejércitos contrarios.

PALABRAS CLAVE:

prostitución, conflicto armado, género, trabajo sexual, masculinidad

This article presents two cases of victimization of female sex workers in the armed conflict context in the cities of Manzanares and Samaná, Caldas. In methodological terms, the research was presented from a qualitative perspective that establishes a centrality of the survivors and witnesses' testimony and narrative of the facts that allow the key reconstruction of historical memory. The findings allow to infer that tolerance zones, bars, and canteens where prostitution is exercised are configured in small mountain villages, border places, thresholds between urban and rural areas, red zones and time bombs as they constitute centers of information circulation and social regulation by regular and irregular armies, making them a perfect target for actions of social cleansing and forced displacement based on stigma and the signaling of cooperation to opposing armies.

\section{KEYWORDS:}

Prostitution, Armed Conflict, Gender, Sex Work, Masculinity 



\section{Introducción}

La comprensión del conflicto armado en Colombia ${ }^{1}$ ha implicado la incorporación de lentes de reflexión distintos a los que se han utilizado en otros contextos de guerra como Centroamérica y África; el caso colombiano se instaura como uno de los primeros que integra los análisis de género desde una apuesta institucional (Centro Nacional de Memoria Histórica [CNMH], 2013). Bajo esta óptica, se han producido sendos informes sobre violencia sexual hacia las mujeres (CNMH, 2012; 2017; Comisión Nacional de Reparación y Reconciliación [CNRR], 2011) y sobre las poblaciones LGBT (CNMH, 2015). A pesar de esta centralidad del enfoque de género, una de las agendas que ha sido relegada y que apenas está tomando fuerza es la situación de las trabajadoras sexuales en el contexto del conflicto armado, en tanto configuran, de alguna manera, coordenadas prohibidas del deseo y la sexualidad, sexualidades disidentes bajo un régimen de sexo/género (Butler, 2007; Rubin, 1986). Por el lado institucional, el Registro Único de Víctimas no permite identificarlas como una población específica con sus propios derroteros.

Una de las estrategias utilizadas por los grupos armados en el marco del conflicto armado en Colombia es el control y la gestión de la prostitución (y de la sexualidad en general) en los territorios de confrontación y dominación (CNMH, 2017; Nieto, 2008). Existen algunos informes que señalan el desplazamiento y las amenazas contra mujeres prostitutas cisgénero y transgénero (CNMH, 2017; Escuela de Estudios de Género, 2015; Nieto, 2008). En otros reportes, se menciona el control comercial, sanitario y legal de las zonas de tolerancia, las mujeres, las cantinas, las tarifas y los clientes (CNMH, 2017; Nieto, 2008; 2013; 2015). También se señala la tortura y el asesinato de mujeres trabajadoras sexuales (CNMH, 2017). En reportajes periodísticos, se da cuenta de la retención masiva o el tráfico de mujeres en zonas cocaleras, de producción de petróleo o minería ilegal, especialmente por parte de paramilitares (ABColombia, 2013; CNMH, 2017; Nieto, 2008). De igual forma, han sido documentados casos de inducción a la prostitución, sobre todo en menores de edad, por parte de actores armados (ABColombia, 2013; CNMH, 2017), y están probados algunos casos de esclavitud sexual (ABColombia, 2013; CNMH, 2017). A pesar de las situaciones documentadas en los reportes, aún existe un fuerte subregistro y

1. El conflicto armado en Colombia tiene una historia de más de sesenta años que se remonta a la violencia partidista de los años cuarenta y cincuenta del siglo XX, transita hacia una confrontación de guerrillas rurales desde los años sesenta y pasa por la emergencia de grupos paramilitares, asociados al narcotráfico, desde los años ochenta. En este escenario complejo de confrontación, diferentes gobiernos han adelantado procesos de negociación con los actores armados, el más reciente con el grupo denominado FARC-EP, que se encuentra en proceso de implementación. El escenario de confrontación bélica ha dejado más de 300 ooo muertos, 8 millones de desplazados y pérdidas incalculables para la sociedad y la economía nacional. 
poca documentación acerca de las situaciones vividas por parte de las trabajadoras sexuales en el marco del conflicto armado como hechos de violencia sexual contra esta población ${ }^{2}$; sus voces aún están silenciadas y sus muertes están pendientes de ser reconstruidas en clave de memoria histórica.

La comprensión de la violencia sexual en el conflicto armado colombiano, desde una perspectiva de género, implica precisar que este no solo contiene una dimensión militar, de confrontación, de lucha y control territorial y de los recursos naturales, sino que abarca espacios, tiempos y actuaciones que van más allá de la cronología y geografía de la disputa armada y que se enraízan en las relaciones de género (Ambos, 2012; Cifuentes, 2009; Pinzón, 2009). Ruth Stanley (2007) sostiene que los imaginarios de género en contextos de guerra reafirman el orden y el orden de género. La autora hace la distinción entre orden y orden de género para subrayar que las representaciones de género en la guerra no solo refuerzan el orden dado de género, sino que sirven asimismo para reforzarlo en un sentido más general-el orden y las jerarquías dentro de culturas, naciones, estados (Stanley, 2007)-.

2. No es objeto de este trabajo asumir una u otra postura respecto a los modelos jurídicos, políticos y analíticos más clásicos para pensar y regular la prostitución: el abolicionismo, el prohibicionismo y el reglamentarismo, con un componente laboralista. De acuerdo con Elvira Villa (2010), cada uno de estos modelos o sistemas de pensamiento plantea una relación compleja, altamente ideologizada, entre género, cuerpo y sexualidad. Para Hurtado (2015), las propuestas que buscan abolir y prohibir la prostitución y el mercado del sexo se articulan alrededor de cinco ejes: 1) el médico o higienista, centrado en el riesgo de propagación de enfermedades de trasmisión sexual; 2) el psicopatológico, que concibe la prostitución como un comportamiento desviado con connotaciones negativas para las personas que la ejercen; 3) el eje jurídico, articulado con la política de legalización o criminalización de su práctica; 4) la dimensión de derechos humanos, la trata y la lucha contra la violencia de género; 5 ) y la noción de libertades individuales y de las mujeres, bajo la idea de que los sujetos toman decisiones y actúan, con base en el nivel estimado de riesgo que desean experimentar, de una u otra forma. La intención es reconocer la complejidad del debate que se cierne al intentar comprender la prostitución y el trabajo sexual en el marco del conflicto armado en Colombia; en este contexto, es más productivo considerar analíticamente una noción abiertay en tensión de prostitución como un universo relacional, imaginativo, político (Nieto, 2013) y moral, que se intersecta con otras nociones más específicas como industria sexual, trabajo sexual o explotación sexual. Para la Escuela de Estudios de Género (2015), la prostitución es un hecho social total, de alta complejidad, que comprende el conjunto de procesos socioculturales que implican la mercantilización-monetarización de los intercambios sexuales. En el caso colombiano, no es fácil plantear si lo vivido en el marco del conflicto armado permite una mirada dicotómica desde posturas abolicionistas o reglamentaristas. Lo documentado por varios autores es que existe un continuum de relativa libertad y coerción, de trabajo libre y forzado (Hurtado, 2015), de autonomía y explotación (Nieto, 2015), de limpieza social, desplazamiento con reconocimiento, de explotación y esclavitud sexual como capacidad de movimiento. En una sociedad tan compleja y porosa como la colombiana, pueden existir posturas diferenciadas por niveles territoriales, momentos históricos y actores involucrados en los diferentes escenarios del conflicto armado. 
Como lo advierte el informe Aniquilar la diferencia, las violencias en Colombia tienen el propósito de "consolidar un orden moral ${ }^{3}$ favorable a los intereses de poder de los actores armados, un orden moral que tiene marcas de raza y clase, pues ha involucrado con mayor fuerza a clases populares" 4 (CNMH, 2015: 25). El sustrato es la forma como son comprendidas las relaciones de género, los imaginarios sobre lo que significa ser hombre o mujer en determinado contexto, lo que es una buena y mala mujer, las putas y las santas, las de familia y aquellas de la vida alegre, con una sexualidad descontrolada, por fuera de las normas morales. Estos imaginarios y representaciones sociales, altamente ideologizados, constituyeron el lienzo sobre el cual desplegaron sus acciones de violencia, en este caso sexual, los actores armados.

Por violencia sexual entendemos, al igual que el informe La guerra inscrita en el cuerpo. Informe nacional de violencia sexual en el conflicto armado:

una modalidad de violencia de género, que se constituye en un ejercicio de poder y dominación ejercido violenta y arbitrariamente a través de la imposición de realizar o presenciar actos sexuales en contra de la voluntad de una persona (...) es una acción racional que responde a la capacidad y voluntad de someter a otra persona que se encuentra en estado de indefensión y/o vulnerabilidad. La violencia sexual reduce a las personas a la incapacidad de decidir y de tener autonomía sobre su propio cuerpo, así como sobre sus derechos sexuales y reproductivos. (CNMH, 2017: 20)

De acuerdo con Segato (2013:20), la violencia de género es utilizada por los perpetradores para expresar control sobre un territorio-población y "sobre el cuerpo del otro como anexo a ese territorio"; es un fenómeno que presenta un alto grado de variabilidad según el actor armado perpetrador, es complejo, multicausal (Wood, 2015) y rizomático.

Dentro del informe nacional, se consideran distintas modalidades de violencia sexual. La más frecuente es la violación, pero también incluye la esclavitud sexual,

3. Subrayado propio.

4. Para Rita Laura Segato (2002: 115), la "violencia moral es todo aquello que envuelve agresión emocional, aunque no sea ni consciente ni deliberada. Entran aquíla ridiculización, la coacción moral, la sospecha, la intimidación, la condenación de la sexualidad, la desvalorización cotidiana de la mujer como persona, de su personalidad y sus trazos psicológicos, de su cuerpo, de sus capacidades intelectuales, de su trabajo, de su valor moral. Y es importante enfatizar que este tipo de violencia puede muchas veces ocurrir sin ninguna agresión verbal, manifestándose exclusivamente con gestos, actitudes, miradas. La conducta opresiva es perpetrada en general por maridos, padres, hermanos, médicos, profesores, jefes o colegas de trabajo" y actores armados. La noción de violencia moral puede traducirse en una geografía moral y del miedo que viven las mujeres en el marco del conflicto armado, siendo una de las expresiones de ese orden moral, donde además se involucra la violencia sexual. 
prostitución, esterilización y aborto forzado (CNMH, 2017). Elisabeth Wood (2009), a partir de sus múltiples investigaciones, incluye como repertorios de violencia sexual la tortura y la mutilación sexual, la esclavitud sexual y el embarazo forzado. Amnistía Internacional (2004) ha recogido testimonios sobre cómo los grupos armados han irrumpido en la vida cotidiana de las poblaciones, tanto rurales como urbanas. Los castigos por el incumplimiento de normas de conducta incluyen la flagelación, la aplicación de pegamento en los cabellos, las rapaduras, las mutilaciones o la desfiguración del rostro y de zonas del cuerpo con ácido o instrumentos cortantes. También es frecuente la humillación pública o desnudar a la persona y obligarla a realizar tareas con un cartel que indica la supuesta falta cometida.

La violencia sexual es una grave violación de los derechos humanos que tiene lugar tanto en tiempos de paz como en contextos de conflicto armado, reconociéndose que los conflictos tienden a exacerbarla (Orduz, 2015; Sørensen, 1998; Wood, 2009) y a percibir diferencialmente las acciones de dominación y agresión sobre el cuerpo de las mujeres, tanto en su acepción individual como colectiva (Olujic, 1998). La violencia sexual afecta a mujeres, hombres, niñas y niños. Es perpetrada mayoritariamente por hombres -aunque ocasionalmente también hay mujeres perpetradoras- $y$ las víctimas son mayoritariamente mujeres -aunque también hay hombres que resultan afectados-(Moser; Clark, 2001). En los contextos de conflicto armado, además de ser una violación de los derechos humanos, también constituye una violación del Derecho Internacional Humanitario (Ambos, 2012; CNMH, 2017; Wood, 2009).

En las seis décadas de conflicto armado en Colombia, todos los ejércitos -fuerzas de seguridad del Estado, paramilitares, guerrillas y grupos armados posdesmovilización (GAPD)- han abusado o explotado sexualmente a las mujeres y han intentado controlar las esferas más íntimas de sus vidas. De acuerdo con la Corte Constitucional de Colombia (2008), la violencia sexual es una práctica sistemática, habitual y generalizada en el conflicto colombiano. Una encuesta realizada por organizaciones de mujeres en un período de nueve años (2000-2009) estimó que 12809 mujeres fueron víctimas de violación, 1575 habían sido inducidas a la prostitución,

5. Desde la academia, organismos multilaterales y organizaciones que trabajan con hombres víctimas de violencia sexual se han alertado del silenciamiento de este fenómeno. Esta situación se ve favorecida por las dificultades de los hombres para reconocer que han sido víctimas de este tipo de abusos, en buena parte por los estereotipos de género que les impiden admitir los hechos sin que su hombría sea cuestionada. Junto a la vergüenza, el miedo y el temor a la estigmatización, pesa el hecho de que la condición de víctima no parece compatible con la idea de masculinidad, en especial en contextos en los que se sanciona socialmente que los hombres expresen o compartan sus emociones (Ambos, 2012). Según estos cánones, el hombre víctima de abusos sexuales debería haber sido capaz de prevenir el ataque y, tras haberlo sufrido, lidiar con el asunto como un hombre (Kumar, 2001). 
4415 habían tenido embarazos forzados y 1810 tuvieron abortos inducidos ${ }^{6}$ (ABColombia, 2013). El Observatorio de Memoria y Conflicto (OMC) del CNMH, con corte al 20 de septiembre de 2017, contabilizó 15076 personas víctimas de delitos contra la libertad y la integridad sexual en el marco del conflicto armado, siendo la mayor parte de ellas (91,6 \%) niñas, mujeres adolescentes y adultas. En relación con los perpetradores, el OMC registra que los paramilitares han sido responsables de 4837 casos, es decir, el 32,2 \%; a las guerrillas se les atribuyen 4722 casos, es decir, el 31,5 \%; los agentes del Estado han sido responsables de, por lo menos, 206 casos registrados, y a los GAPD se les imputan 950. Hay un importante número de casos en los que no se ha establecido el responsable: 3973 .

\section{Contexto y metodología de investigación}

Manzanares y Samaná son dos municipios andinos asentados en las laderas orientales de la Cordillera Central en el departamento de Caldas, Colombia. Sus fundaciones datan de finales del siglo XIX, en el marco de la colonización antioqueña. La economía local se basa en la explotación agropecuaria, con una fuerte dependencia del cultivo y comercialización del café. La bonanza cafetera de los años setenta y ochenta del siglo pasado consolidó una economía agrícola local basada en la producción y comercialización del grano e impulsó un encadenamiento de otros sectores económicos como el comercio y los servicios. No obstante, la caída del pacto internacional del café, en 1989, y sus consecuencias, que se vivieron durante la década de los noventa, con prolongación hacia el siglo XXI, coincide con los primeros brotes de insurgencia en el departamento, especialmente en los municipios del oriente de Caldas, con presencia, además, de cultivos ilícitos y narcotráfico (Palacio; Cifuentes, 2005).

La década de los noventa y el primer lustro del siglo XXI se reconoce como un período de agudización del conflicto armado en el departamento de Caldas, años en los cuales hubo una fuerte presencia guerrillera en cabeza del Frente 47 de las FARC-EP y se asentaron grupos paramilitares. Al momento de hacer el trabajo de campo, la intensidad del conflicto había menguado en estos territorios y, por lo tanto, habían disminuido drásticamente las operaciones militares, situación que generaba entre los pobladores una sensación de calma y tranquilidad.

Para comprender los hechos victimizantes, se adelantaron diez entrevistas a profundidad con actores claves de la vida municipal que permitieran comprender 
lo ocurrido con estas poblaciones en el marco del conflicto armado entre los años 1985-2015. Dentro de los criterios de inclusión fue básico que las personas hubiesen vivido en el municipio durante el momento más crítico del conflicto armado y que fueran testigos de los hechos victimizantes relatados. También se adelantó una revisión en prensa institucional, en los diarios La Patria y $Q^{\prime} h u b o$, en el mismo período de tiempo. Ambas rutas forman parte de un diseño de investigación cualitativo que orientó todo el proceso de diseño, trabajo de campo y análisis de la información.

En principio, los relatos de los hechos victimizantes no se centraron en trabajadoras sexuales sobrevivientes del conflicto armado, pues se debe reconocer en ellas una alta movilidad entre poblados y caseríos. El mercado sexual en estos poblados andinos, asociado a la prostitución en cantinas y bares, es muy dinámico y tienes niveles de saturación rápidos que implican una alta rotación de las mujeres y, por lo tanto, su poco arraigo en las localidades, salvo casos excepcionales. Por esta situación, durante el trabajo de campo no se encontraron mujeres víctimas del conflicto armado que hubiesen ejercido o ejerciesen la prostitución en el período en estudio. Esa condición ha sido más común encontrarla en zonas de expansión de la frontera agrícola, cocaleras, de explotación minera o en ciudades intermedias y capitales receptoras de desplazamiento (CNMH, 2017).

Lo que sí emergió durante el trabajo de campo fueron relatos sobre la muerte de dos grupos de trabajadoras sexuales, una ocurrida en el municipio de Manzanares, en el sector de Casa Roña, y la otra, en el municipio de Samaná, en el sector de Buenos Aires; ambos lugares constituían las zonas de tolerancia en las postrimerías del siglo XX cuando ocurrieron los hechos. Lo que llama la atención es la forma como estas muertes están instaladas en la memoria colectiva de los habitantes que (sobre)vivieron al conflicto armado en estos dos municipios. La reconstrucción de los hechos, de cómo rescatar la experiencia vivida (Simons, 2011) por otros no presentes, plantea cuestionamientos sobre cómo narrar las muertes olvidadas, no documentadas y registradas por la investigación criminal o la prensa oficial, y llevarlas a la voz pública, haciendo de la investigación científica no solo un asunto académico, sino de compromiso político con las víctimas y la memoria histórica y colectiva.

En este sentido, durante la visita al municipio de Manzanares, el corresponsal del periódico La Patria me enseñó su archivo de más de veinte años con las noticias en las cuales él había sido el reportero; era una carpeta voluminosa. Al preguntársele por qué no existía registro periodístico sobre la masacre de las trabajadoras sexuales en Casa Roña, expresó con voz segura "que esas muertes no le interesaba cubrirlas, eso no le importaba a nadie, él no perdía el tiempo haciendo ese tipo de reseñas" (Juan, comunicación personal, 18.07.2017). El aparato judicial local también actúa de una manera similar frente a la muerte de poblaciones estigmatizadas o indesea- 
bles en los territorios. Pareciera que este tipo de poblaciones no tuviera derecho a la memoria por el estigma social que pesa sobre ellas. Tal vez, como lo recuerda María Victoria Uribe (2015), sus cuerpos son un cúmulo de muertos, sin nombre y sin justicia, algunas con un apodo o sobrenombre como fueron conocidas, sin que nadie haya podido, o querido, contar sus historias o reivindicar sus memorias.

La construcción del relato sobre estos hechos victimizantes se realizó en dos momentos diferentes. Primero, el investigador enlazó en una descripción densa los testimonios que permitieran la emergencia de un relato que diera sentido a lo descrito por los pobladores respecto a los hechos que vivieron las trabajadoras sexuales en el marco del conflicto armado. Luego, en reuniones con grupos de personas víctimas del conflicto y testigos de excepción de los hechos en los municipios, el texto se puso a prueba. Su lectura permitió hacer precisiones de lo allí descrito e introducir elementos olvidados en las entrevistas a profundidad. Estas reuniones validaron el relato construido como una narrativa instalada en la memoria colectiva y que, por lo tanto, aporta a la memoria histórica del conflicto armado en Colombia.

\section{Resultados de investigación}

Los hallazgos de la investigación se presentan en los siguientes cuatro apartados que narran, a modo de relato etnográfico, las masacres ocurridas a dos grupos de trabajadoras sexuales en los municipios referidos?.

7. Lo ocurrido con las trabajadoras sexuales en los dos municipios debe ser considerado una masacre, según los atributos establecidos por María Victoria Uribe (2004: 6), en tanto dicha noción es aplicable a las muertes colectivas que se "inscriben al menos en dos registros, en el ámbito social local y en el ámbito subjetivo. En el ámbito social local, las masacres son eventos devastadores que afectan profundamente tanto a las personas directamente afectadas como a las comunidades a las cuales pertenecen. En el ámbito subjetivo, las masacres tienen un efecto devastador, según se deduce de los testimonios de los sobrevivientes que narran los hechos". No obstante, al tratarse de muertes en poblaciones altamente estigmatizadas, como poblaciones LGBT, putas y viciosos, sus vidas tensionaban el orden moral de los territorios y, por lo tanto, sus muertes, a manos de actores armados, fueron celebradas en muchos lugares como acciones de limpieza social necesarias para restablecer un orden en decadencia. En tal sentido, las nociones de ámbito social local, memoria colectiva e impacto subjetivo de muertes colectivas en estas poblaciones deben leerse con cuidado y precisión, en tanto presentan configuraciones diferentes de aquellas muertes colectivas de personas moralmente deseables en los territorios: campesinos, obreros, sindicalistas, líderes sociales, entre otros. 


\section{“iQué bueno! Están limpiando el pueblo de basura": las masacres de prostitutas en Manzanares y Samaná}

Tuve la fortuna de conocer a Azul ${ }^{8}$, una mujer trans de Manzanares, en un encuentro departamental de víctimas. La primera vez que compartí con ella fue en el vestíbulo de un hotel modesto en el centro de la ciudad de Manizales. En la conversación, le expresé nuestras intenciones de investigar con población LGBT y prostitución en el marco del conflicto armado, y el valioso apoyo que ella, como delegada, podría brindar para este propósito. Acordamos una fecha para visitar Manzanares en noviembre del año 2016.

La mañana que llegamos hacía frío, estaba nublado y lloviznaba. Manzanares es un pueblo andino caldense, en las estribaciones orientales de la Cordillera Central. Estando en la plaza principal, nos acercamos a la Alcaldía para intentar conversar con el alcalde y el secretario de Gobierno y hacer públicas nuestras intenciones como investigadores, el apoyo institucional que demandaríamos y la posibilidad de acceder a fuentes de información institucionales sobre hechos victimizantes.

Desde las primeras conversaciones con funcionarios y actores claves de la vida municipal, salían a flote historias instaladas en la memoria colectiva, situaciones que les habían impactado y que permanecían ancladas en los relatos y discursos locales, las cuales emergían siempre en las conversaciones cuando se hacía referencia a los efectos del conflicto en el municipio y a los hechos victimizantes hacia la población LBGT y trabajadoras sexuales. Los informantes mencionaban recurrentemente la masacre de las mujeres en Casa Roña como también la muerte de Tania, de la Chicholina, por defender a una prostituta, y la muerte de Josecito.

En julio del año 2017 regresamos a Manzanares, donde realizamos varias entrevistas con personas clave que habían vivido el período de mayor intensidad del conflicto armado en el municipio, entre los años 1998 y 2006. Por más que los hechos referidos por los pobladores fueron buscados en los registros de prensa y en los expedientes judiciales, la búsqueda fue en vano. De estas vidas, de la forma como vivieron y murieron, solo quedan fragmentos de memoria en aquellos que convivieron con ellas, que las conocieron o que tenían algún referente suyo.

Las muertes de trabajadoras sexuales pueden ser enmarcadas en las operaciones de limpieza social que ejecutaron en los municipios diversos actores armados del conflicto interno que ha vivido el país. Según el texto de Gallego, Yáñez, Rodríguez, Sánchez y Giraldo (2018), la limpieza social es la expresión más utilizada por las personas, las comunidades y los mismos actores armados para referir un conjunto

8. Todos los nombres que aparecen a continuación son ficticios para proteger la identidad de las personas que participaron en la investigación. 
de acciones de señalamiento, hostigamiento, control militar y territorial, y a veces hasta la muerte hacia poblaciones indeseables, menospreciadas, estigmatizadas en los municipios. "Es una 'limpieza' -dicen quienes perpetran esos crímenes-, queriendo significar que se ocupan del acto de remover la inmundicia y la suciedad. Los cuerpos que yacen portan consigo una marca de identidad" (Perea, 2015: 7). Identidades muy bien definidas en los panfletos que anuncian la limpieza: consumidores de drogas (bazuqueros), trabajadoras sexuales (putas), hombres afeminados y poblaciones de lesbianas, gais, bisexuales y transgéneros, lo que se conoce como población LGBT (sidosos).

Las operaciones de limpieza social que ejecutaron los actores armados fueron una herramienta, hasta cierto punto, justificada por las mismas comunidades, en un esfuerzo por hacer prevalecer un orden y el restablecimiento de las buenas costumbres. La limpieza social se veía como una forma de controlar y disciplinar las comunidades, utilizando el escarmiento y las muertes selectivas como señal del mal comportamiento. De ahí la importancia de la identidad de ese cuerpo, un cuerpo generizado, pero también racializado. El propósito de la limpieza como dispositivo de control no es solo la dominación de los cuerpos y las subjetividades, sino también la administración de la bio y la necropolítica, como ha sido descrita por Mbembe (2011). También las acciones de limpieza social implicaban un control del tiempo y el espacio. Las guerrillas y los grupos paramilitares instauraron los tradicionales toques de queda, unos controles para permanecer en la calle hasta ciertos horarios, y también establecieron prohibiciones para circular por determinadas calles, reunirse en los parques, visitar ciertos lugares, incluyendo cantinas y prostíbulos.

\section{La muerte de las mujeres que hacían salón en Manzanares}

Sara es una mujer portadora de una memoria prodigiosa sobre hechos y situaciones relacionadas con el conflicto armado en el municipio. Nos relata que las mujeres trabajadoras sexuales que llegaban al municipio provenían de Medellín, Manizales y Pereira: "Las tres chicas que mataron eran amigas, venían de muy buena familia, muy lindas, a mí me tocó verlas [muertas] en el cuerpo de bomberos, muy bien vestidas, muy elegantes y muy jóvenes" (Sara, comunicación personal, 18.07.2017). Las chicas llegaron a ejercer la prostitución en un lugar que se llamaba Ana Beiba.

La reconstrucción de lo sucedido está tejida en un escenario polifónico, memorias de lo visto y lo olvidado, también lo magnificado por la memoria, lo contado por otros e interpretado por quien escuchó el relato. El hecho ocurrió al amanecer, el sábado 11 de noviembre de 2001. 
Mi padrastro y mi mamá vivían antes de llegar a la bomba y mi padrastro todos los días salía a las 5:30 de la mañana para la finca y se tenía que meter por ahí, por el estanquillo, justo donde estaban todas esas casas de citas. Estaba muy oscuro. Me cuenta mi mamá que eran como las 5:30 cuando él vio algo tirado a todo el frente de Casa Roña, pero Ana Beiba estaba ahí a diez metricos. Como vio algo tirado allá, se fue y vio tres mujeres tiradas sobre el puente, no en el río, sino en el puente, sobre la vía. Él vio mucha sangre, fue muy traumático, se devolvió, no fue capaz de seguir para la finca. (Sara, comunicación personal, 18.07.2017)

En este mismo relato coincide Margarita, una líder local, quién agrega: "A ellas las desfiguraron totalmente, golpeándolas. Había una de ellas que tenía cuatro meses de embarazo. Las degollaron de oreja a oreja, las dejaron tiradas por el puente. Las dejaron tiradas en el piso boca abajo" (Margarita, comunicación personal, 19.07.2017). Según Sara, a las seis de la mañana recibió una llamada de su madre para alertarla del hecho. Sara manifestó que esperaría que fuesen las 7:30 de la mañana "para ir a hablar con el personero". Llegada la hora, el hecho fue comunicado y el personero decidió llamar y organizar con la Policía el levantamiento de los cuerpos. Margarita recuerda que durante el levantamiento y al voltearlas boca arriba, "la cabeza casi se les caía, eso fue impresionante". Agrega:

Las caras de ellas no eran redondas, sino como cuadradas de los golpes que les dieron. Se las llevaron y dicen que las mataron en otro lado, porque para ser una muerte tan horrible ahíno había tanta sangre como para eso. (Margarita, comunicación personal, 19.07.2017)

De acuerdo con Margarita, las chicas que se llevaron fueron cinco: dos de ellas lograron sobrevivir y tres fueron asesinadas:

Una de ellas después contaba que se metió en un huequito muy pequeño, no supo del miedo, del susto, se metió detrás de una nevera. La otra cogió por el lado de la quebrada, cogió quebrada abajo y alcanzó a salir y se voló. Pero las otras tres chicas no contaron con la misma suerte, pero nunca se supo por qué. (Margarita, comunicación personal, 19.07.2017)

Sobre las causas o móviles de los hechos se puede especular mucho. Siguiendo a Sara, "las versiones eran que una de ellas estaba en embarazo de uno de los comandantes de las autodefensas, pero igual nunca se supo”. Según ella:

Hace poquito, una tal Rihanna vino al pueblo y nos contó que ellas hacían salón ahí donde Ana Beiba. [Esa noche] llegaron unos tipos en unos carros muy lujosos, se bajaron, entraron, como que las venían siguiendo, le pagaron a la señora Ana Beiba para 
podérselas llevar, como que le dijeron: "Ellas no van a ser salón hoy acá, nosotros le vamos a pagar la noche a ellas". Y les dijeron a ellas: "Les vamos a pagar a ustedes, queremos irnos a tomar a otro lado”. Eran por ahí las 2:30 de la mañana, Ana Beiba recibió la plata y los hombres se fueron con las mujeres. Ni siquiera Ana Beiba se había dado cuenta de que las habían matado. Ellas no volvieron, dijeron que las llevaban al otro día. Dijeron que era por una venganza de no sé qué, de unos tipos, no se sabía si eran paramilitares o guerrilleros, nosotros no supimos por qué las familias [de las mujeres] se dieron cuenta y vinieron a recoger los cuerpos a los ocho días. (Sara, comunicación personal, 18.07.2017)

\section{La masacre de prostitutas en la zona de Buenos Aires, Samaná}

El día que llegamos a Samaná, en el mes de julio del año 2017, fuimos atendidos por un egresado de la Universidad de Caldas quien, muy amablemente, nos orientó por el pequeño poblado y nos ayudó a instalar en un modesto hotel. En la noche salimos a comer a un restaurante ubicado en la vía que conduce a lo que queda de la zona de tolerancia del municipio, denominada Buenos Aires y La Plazuela. En medio de la conversación con las dueñas del restaurante sobre la historia del municipio y del tipo de clientela que la frecuentaba, salió a flote la masacre de tres trabajadoras sexuales y otros hechos ocurridos en este sector durante los años más críticos de la violencia armada.

Contaba una de las meseras que los hechos ocurrieron el 19 de julio de 1996. Esa noche mataron a tres mujeres: la Gomela, quien era la más famosa de la zona, y dos mujeres más de las cuales se tenía poca información, nunca se supo con precisión su procedencia o nombre. A una de ellas le pegaron una puñalada en una pierna y murió desangrada en la calle. A la Gomela y a otra chica, afirmó, las tiraron al río La Miel para desaparecerlas. Comenta que los bomberos hicieron la búsqueda, pero solo encontraron el cuerpo de la Gomela, a quien se le dio sepultura en el cementerio local.

Para Romelia, una mujer octogenaria, quien fue dueña y administradora de una de las cantinas de la zona, a las chichas las mantenían amenazadas los diferentes grupos armados que hacían presencia en la zona: "A la Gomela yo le había dicho que le daba el pasaje para que se fuera [de Samaná], que salvara su vida. Pero ella no quería irse sola, entonces convidó a otra muchacha" (Romelia, comunicación personal, 22.07.2017). La noche que las mataron, advirtió Romelia, venían por la Gomela, mas no por las otras chicas. En medio del agite se llevaron las tres mujeres y concluyó: "La que iba con la Gomela estaba embarazada y de ella nunca se supo que pasó, no hallaron el cuerpo" (Romelia, comunicación personal, 22.07.2017). La información respecto al grupo armado que perpetró el hecho es contradictoria. Para las dueñas del restaurante, fue la guerrilla, mientras que, para Romelia, fueron los 
paramilitares. Lo que sí parece estar claro es que sobre este grupo poblacional se cernían amenazas constantes al considerarlas informantes de uno u otro grupo y de los mismos policías que rondaban la zona.

Para comprender mejor los hechos, nos desplazamos al día siguiente donde el comandante de bomberos del municipio, institución que durante los años más críticos del conflicto armado fungió como medicina legal, fiscalía y hasta policía en zonas del municipio donde la presencia del Estado estaba evaporada o era escasa. Cuando ocurría un crimen, era el cuerpo de bomberos el que hacía el levantamiento y elaboraba, en un libro de actas, una descripción a mano alzada de lo sucedido y visto en el lugar. En medio de la visita, el libro de actas fue sacado celosamente de un archivo y el comandante fue relatando, según su criterio, las muertes que más impactaron a los samaneños. De acuerdo con su relato, cada registro de un levantamiento evoca una forma de cómo sucedieron los hechos; a unos les dedicaba más tiempo que a otros. En la página 61 de este libro aparece la descripción de la muerte de la Gomela y la forma en que ocurrió el levantamiento del cuerpo. El número de registro, el 787, describe lo siguiente: "Homicidio NN, ante este despacho el día 19 de julio del 96 fue enviado a la unidad seccional de fiscalías de La Dorada, Caldas. Se pudo establecer que la occisa no respondía a ese nombre, al parecer respondía al nombre de Angélica Rodríguez Valencia, natural de Pereira".

De esta masacre, como la ocurrida en Manzanares y muchas otras de la geografía nacional hacia la población de prostitutas y otras poblaciones indeseables en los municipios, no hay registro en prensa, no hay expedientes judiciales o las pocas huellas escritas de lo sucedido fueron borradas por el paso de los años.

\section{Los prostíbulos como bombas de tiempo y zonas rojas en los municipios que viven en conflicto armado}

Una pregunta inicial puede orientar y detonar la reflexión final sobre el ejercicio de la prostitución en zonas de conflicto armado, cuestión relacionada con el origen geográfico de las mujeres cis y transgénero que habían llegado a este par de municipios andinos a participar del mercado sexual. Según los relatos de las entrevistadas, la prostitución y las casas de citas florecían en Manzanares y Samaná antes y durante los primeros años de agudización del conflicto armado. La bonanza cafetera de los años setenta y ochenta del siglo pasado permitió una consolidación de una economía local que consentía que parte de sus excedentes fuesen invertidos en sexo, licor y diversión en las cantinas y prostíbulos de la zona de tolerancia.

En aquellos años, Manzanares y Samaná contaban con zonas de tolerancia bien definidas: en el primer municipio existían Casa Roña y Casa Verde como lugares 
que concentraban una cantidad menor de cantinas y bares donde se ejercía la prostitución. En Samaná existieron tres zonas: El Barrio, Buenos Aires y la salida para Pensilvania. Las zonas de tolerancia no solo eran lugares donde se comercializaba sexo, sino que constituían lugares de reunión, encuentro y esparcimiento de hombres, en una lógica típicamente patriarcal de construcción del deseo.

Según el relato de Sara, en plena cosecha y bonanza cafetera, llegaban más de cien mujeres semanales a Casa Roña:

Los jueves por la mañana, o los viernes en la mañana estaban llegando, como se dice vulgarmente camionados. Como decían todos los hombres del pueblo, llegó ganado nuevo, a estrenar. Traían mujeres muy lindas, contrataban carros para traerlas, mejor dicho, cada ocho días renovaban el tendido. Cada ocho días venían y se iban, se las llevaban. Los dueños de estos sitios iban y buscaban mujeres nuevas, o sea, que los hombres no se cansaran de ver las mismas de siempre, siempre estaban cambiando, más que todo el dueño de Casa Roña [...]. El ya murió, a él también lo mataron, siempre buscaba por medio del hijo y amigos de Medellín y de otras ciudades: "Búsqueme las mejores mujeres, que aquí mejor dicho todos los hombres se desbocan por ellas”. (Sara, comunicación personal, 18.07.2017)

Según el relato de Margarita, "llegaban muchas universitarias, porque en ese entonces yo vivía con mi esposo y él traía chicas. Le pagaban para ir a traer chicas de otros lados, y traía de Manizales, Fresno, Mariquita, Dorada, [...]. Eran chicas de un buen nivel educativo por lo que conversaban" (Margarita, comunicación personal, 19.07.2017). En esa época, agrega:

Trabajan unos carritos que les dicen los periféricos, los llaman los casarroñeros, y por la noche, transportaban clientes del pueblo a la zona. Un fin de semana se hacían divinamente doscientos, trescientos mil pesos en un fin de semana. [G: ¿En un fin de semana subiendo y bajando gente?] Sí, subiendo y bajando, y cuando eso las carreras eran a $\$ 1500$ a $\$ 1000$, entonces se movía... y como siempre era tan arriba, porque es la salida del pueblo, eso era impresionante y allá habían cenaderos donde usted iba a comer. Incluso había gente que no utilizaba la zona de tolerancia, sino que iba a comer allá en los cenaderos, porque era delicioso, gallina criolla todo eso así, había unas tiendas muy bien surtidas donde usted conseguía de todo. (Margarita, comunicación personal, 19.07.2017)

En su relato, la informante agrega que a las mujeres económicamente no les iba mal:

Había unas que se sacaban cuatrocientos, quinientos, ochocientos mil pesos, yo llegué a ver una muchacha contando millón doscientos, y eso es mucha plata para 
un municipio y en esa época, y en eso es que uno se queda aterrado de que sí les iba superbien, y aquí la economía, aquí se movía mucho, demasiado. (Sara, comunicación personal, 18.07.2017)

Relatos similares pueden ser hallados para el municipio de Samaná y su zona de tolerancia. Para Romelia, antes y en los primeros años del conflicto, el negocio era bueno, "subía mucha gente al negocio".

Como puede entenderse en los relatos, las zonas de tolerancia constituían un imán, un punto de encuentro en la vida cotidiana de estos pueblos andinos. Durante la agudización del conflicto armado, en los bares y cantinas de la zona confluían diferentes actores armados, tenían sus horarios y días de visita. Al encontrarse las zonas en lugares de borde, límites entre lo urbano y lo rural, constituían fronteras, zonas de tensión, pero al mismo tiempo de encuentro entre las guerrillas -con una fuerte presencia rural-y los paramilitares -con un control territorial urbano-. Un habitante del municipio de Samaná con quien compartí un café me comentó en medio de la charla que en el bar Fantasías, en la zona de tolerancia, integrantes de las guerrillas y los paramilitares se mezclaban con las mujeres en el baile; por este hecho, la gente del pueblo decía que ese lugar era una bomba de tiempo que en cualquier momento podría explotar.

El Ejército y la Policía también eran clientes asiduos de los prostíbulos. Cuenta Romelia que personas de diferente rango-capitanes, coroneles, policías y soldados rasos- visitaban el lugar, bebían, bailaban y terminaban en cama con una de tantas mujeres. Afirma que allí nacieron historias de amor, romances, vinculaciones a grupos armados, pero también espionajes, intercambios de información, deserciones y huidas. Tal vez por eso las trabajadoras sexuales, en el marco del conflicto armado, fueron miradas con un doble racero: por un lado, compañeras para el amor y el sexo en un contexto militar de guerra; por otro, confidentes peligrosas, depositarias de muchos secretos que las hacían presas de constantes amenazas, como afirma Romelia sobre la historia de la Gomela.

En efecto, según el relato de Romelia, las zonas de tolerancia en los municipios estaban declaradas como zona roja ${ }^{9}$ por parte del Ejército y la Policía. Ella, al referirse al asesinato de un policía que ocurrió en la zona de tolerancia, plantea que increpó a otro uniformado que estaba esperándolo en la zona y le preguntó:

¿Por qué se viene a esperarlo acá, sabiendo que por acá arriba la Policía les tiene prohibido? Esto es zona roja, le tienen prohibido a la Policía subir por acá a pie. Nosotros

9. En Colombia, la declaratoria de una zona como roja implica que en ese territorio se desarrollan hostilidades entre actores armados. 
estamos acá porque sabemos a qué horas tenemos que cerrar, pero usted sabe que esto sí está declarado como zona roja. (Romelia, comunicación personal, 22.07.2017)

Zona roja y bomba de tiempo son expresiones que usa la población en general y los actores armados para referirse a los límites geográficos (zona roja) y temporales (bomba de tiempo) de un entramado espacial complejo, altamente volátil, de circulaciones restringidas, de quién ingresa y quién no, de cómo se circula por el lugar, qué puesto se ocupa, cómo operan los silencios y cómo se infringen los códigos no explícitos.

En efecto, como lo manifestaba Azul, en las zonas de tolerancia había un pacto de silencio: "Lo que ocurría allá, se quedaba allá, nadie comentaba" (Azul, comunicación personal, 20.07.2017). Estos pactos incluían clientes, prostitutas, fisgones, malandrines, vecinos del lugar; lo pactado estaba en el orden de lo íntimo: infidelidades, amoríos, trasgresiones del orden sexual, hombres que buscaban amor y placer en brazos de travestis, pero también este pacto tenía fisuras, derivaciones hacia escenarios de confrontación, hombres guerreros que al frecuentar la zona compartían estrategias de guerra, acciones secretas. En otras palabras, la zona tamizaba el habitus guerrero (Castellanos, 2011) por el deseo. De ahí su volatilidad, su explosión permanente, pero también su contención.

\section{Reflexión final: ejércitos y prostitución militarizada, un continuum en la construcción de la masculinidad guerrera}

Para los habitantes de Samaná y Manzanares, los primeros años de agudización del conflicto armado no vieron una disminución o desaparición de las zonas de tolerancia, de las cantinas y bares o del número de mujeres y hombres que las frecuentaban. Los relatos de algunos habitantes de estos dos poblados manifiestan que el número de lugares destinados para los encuentros sexo-afectivos y de diversión era constante $y$, a veces, incrementaba dependiendo de la presencia de ejércitos en la zona. Lo hallado en estos municipios andinos puede ser concebido como una de las modalidades de prostitución militarizada, como la define Jennifer Butler (2000), para explicar el comportamiento de los militares estadounidenses en territorio asiático $^{10}$. Para el caso específico de Manzanares y Samaná, el número de mujeres

10. La prostitución militarizada la entiende Butler (2000) como el establecimiento de burdeles alrededor de las bases militares para proveer entretenimiento y servicios sexuales a los soldados ocupantes. Usualmente, los dueños de los burdeles compran mujeres y niñas a tratantes o reclutan mujeres en zonas no muy lejanas azotadas por la pobreza o la violencia. Durante la guerra, mujeres y niñas desplazadas de sus tierras y que no cuentan con apoyo familiar se ven forzadas, en muchos casos, a vender sus cuerpos para sobrevivir o mantener a sus familias. A veces son víctimas de violaciones durante la guerra y, por 
incrementó para satisfacer un mercado sexual en alza, como bien lo relataban Romelia y Margarita en el apartado anterior. No obstante, los problemas, amenazas y muertes de clientes, sexoservidoras y otros asiduos visitantes hicieron que, entre los años 2002 y 2004, se diera la orden por parte de los paramilitares de cerrar los negocios de la zona de tolerancia de Buenos Aires, en el municipio de Samaná, y de Casa Roña, en Manzanares. Con el paso del tiempo, los lugares se fueron extinguiendo hasta casi desaparecer.

Según el relato de Margarita y Sara, la zona comenzó a tener problemas después de la masacre:

Ya ese fin de semana pues, las otras, muertas del miedo, y se fue corriendo la voz en todas las chicas y se iban... y disminuyó el número de mujeres. [Menciona un nombre] traía varios viajes de mujeres y luego si acaso dos, y eso porque no sabían, y después de que se daban cuenta, muchas veces llegaban el jueves y el viernes y ya estaban empacando maletas porque se iban a ir. Entonces eso ya no empezó a funcionar, ya no funcionaba, la gente no subía, las carreras no eran lo mismo y empezó a declinar. [G: ¿A decaer los negocios?] A vender los negocios, estuvo [sic] mucho tiempo las casas solas, por ejemplo, hoy en día ya usted va y no parece lo que era antes, la gente de antes sí sabía que era Casa Roña, pero ya son casas familiares. Por ejemplo, la más grande que es la casa del mosco, él cogió y la vendió, la partieron en dos, como dos casas diferentes, y son casas familiares. Hay otra que la están reconstruyendo, que era la de don Javier, y hasta una se volvió iglesia. (Margarita, comunicación personal, 19.07.2017)

Parte de la explicación que dan los habitantes de los municipios tiene que ver con el control que ejercían los paramilitares de las zonas de tolerancia. De acuerdo con el relato de Sara, los paramilitares "eran los controladores más grandes. Ellos tenían el poder, el mando del pueblo". Ese control significaba, como lo hemos documentado unas páginas atrás, vigilancia del tiempo y el espacio de los pobladores, de los recorridos, de la presencia o ausencia en ciertos lugares. Las zonas de tolerancia formaban parte de una franja moral sobre la cual se hacía una gestión de la prostitución (y de la sexualidad en general) en los territorios de dominación (Nieto, 2008), un régimen de escrutinio permanente sobre poblaciones altamente estigmatizadas que circundaban la zona: consumidores de drogas, población LGBT, hombres afeminados y, por supuesto, trabajadoras sexuales, es decir, todo aquello que en sus

ello, se les considera indignas para el matrimonio. A menudo, carecen de educación por la pobreza o por el simple hecho de ser mujeres, situación que les dificulta acceder a empleos que provean un salario suficiente para su manutención. Los soldados ocupantes, según Butler (2000), manejan una moneda fuerte (el dólar) que les permite el acceso a este mercado sexual e incluso pueden ofrecer a las mujeres una huida del país, vía matrimonio. 
esquemas morales formaba parte de una población indeseada, menospreciada, para su proyecto de sociedad.

Gestión, en este contexto, es control, regulación de la sexualidad en un régimen de sexo/género (Gallego, 2011). También esa gestión de la prostitución puede ser leída, al menos en dos de los cinco elementos, en el esquema propuesto por Teodora Hurtado (2015), en tanto la regulación de dicha práctica, por parte de los actores armados, tenía cortes higienistas, centrado en el riesgo de propagación de enfermedades de trasmisión sexual y psicopatológico, al considerarlo como un comportamiento desviado con connotaciones negativas para la sociedad. No es descabellado pensar que una de las hipótesis que explica el cierre de la zona de tolerancia está asociada con los patrones descritos por Hurtado.

El siguiente testimonio relata la forma como los paramilitares ejercían un control en la zona de tolerancia de Manzanares:

Les gustaba subir mucho [a los paramilitares], y ellos decían que era más que todo para mirar quién era el vicioso, porque en esos negocios se metían su marihuana, lo que sea, ellos los iban a identificar más rápido... Cuando a alguien no lo encontraban en el pueblo, subían allá, tenían su payaso [un informante civil] y tenían gente que los llamaba y decían: "Fulano esta acá”, o sutana, o fulana, entonces los ubicaban y allá los mataban [en Casa Roña]. Allá mucha gente buscaba refugio, esconderse, y mentiras que no, porque allá de pronto no estaba el paramilitar reconocido en el pueblo, que lo estaba buscando, pero mandaba a otra persona. "Es fulano de tal, pregunte a tal persona, pregúntele al mesero, a las meseras, a las muchachas que si se encuentran fulano con tal persona...”. "Ah sí, acá está, en tal mesa con tantas mujeres”, o “está en una mesa con tantas personas, está vestido de tal forma”, y ya estaba reconocido. Ahí fue cuando ya empezó a haber tanta muerte, pues Casa Roña desapareció total [sic], porque hasta el dueño también lo mataron, porque también era expendedor de droga y expendía la droga a los mismos visitantes. A la esposa de él también la mataron, y ya los otros, lo de Javier y Amparo, todo eso fue desapareciendo. Después mataron a Jorge que era el de la tienda. Ya nadie abría, estaba pensando en que iban a llegar a matarlo, disminuyó muchísimo la prostitución, claro. (Sara, comunicación personal, 18.07.2017)

Es decir, existe una alta regulación de la prostitución como actividad en la cual los actores armados ejercen un poder directo de control y cocreación de las sexualidades y el género en interrelación con otros marcadores de diferencia presentes en la vida de los municipios. Como lo sugiere Nieto (2008), no es solamente en la zona donde la prostitución y otras formas de sexo transaccional o de participación en los mercados del sexo suceden. Sin embargo, prostitución (sexualidad, afectos, trabajo, corporalidades) y zona operan como espacios imaginarios y materiales de articulación y gestación de formas específicas y parecidas de violencia (Nieto, 2008). 
Finalmente, la forma como operan las zonas de tolerancia, las cantinas y prostíbulos en zonas de conflicto armado hace parte de un teatro de guerra, con instituciones y normas que inculcan una masculinidad altamente militarizada, en la que se despliegan las características de un habitus y una masculinidad guerrera en la forma como ha sido descrita y analizada por Juan Manuel Castellanos (2011) en su tesis doctoral Formas actuales de la movilización armada. Una masculinidad que no solo se despliega sobre formas de habitar y disciplinar el cuerpo del guerrero, de potenciar la fuerza, la virilidad y la demostración de poder, sino de participar de una tropa, de tener control y dominio territorial. También el habitus guerrero tiene un efecto de espejo en otros que valoran el uniforme y las disposiciones corporales propias del hombre de tropa. Para Romelia, administradora de cantinas y prostíbulos en Samaná, algunas mujeres tienen cierta fascinación por el uniformado. Ella sugiere que "las muchachas, usted sabe, algunas mujeres tienen fascinación por las armas, ¿cierto? Les gustan mucho las armas o el policía, o el soldado. Hay mujeres a las que les gusta el uniforme" (Romelia, comunicación personal, 22.07.2017). Iris Marion Young (2003) señala que la masculinidad militarizada requiere de una masculinidad protectora que valida la vulnerabilidad de las mujeres y su dependencia de protección por parte del hombre frente a las dificultades y peligros del mundo. Diríamos que la masculinidad militarizada, en clave de género está permeada por imaginarios tradicionales de femineidad y masculinidad y requiere del deseo para concretizarse.

En tal sentido, las zonas de tolerancia constituían el escenario perfecto de una prostitución y el despliegue de una masculinidad militarizada (Wood, 2009), no solo por las prácticas y regulación de la sexualidad en sus formas simbólicas de circulación de cuerpos, placer, deseo, amor y traición, sino por los modos de regulación del tiempo y el espacio, de recreación de un imaginario de hombres de tropa, valerosos, dispuestos a la protección. No obstante, como el control o la regulación no son categorías totales, siempre existen fisuras que desbocan en violencias, muertes y masacres, tal vez por violar lo instituido, lo pautado, pero también por aquello que se mueve de manera ambigua en el secreto, en la penumbra, pero que produce más daño.

\section{Referencias}

ABColombia (2013). Colombia: mujeres, violencia sexual en el conflicto y el Proceso de Paz. Londres: ABColombia/Sisma Mujer. Recuperado de https://www.abcolombia.org.uk/wp-content/ uploads/2017/o6/4-Sexual-Violence-Spanish.pdf

Ambos, Kai (2012). Violencia sexual en conflictos armadosy derecho penal internacional. Bogotá: Universidad Externado de Colombia. 
Amnistía Internacional (2004). Colombia. Cuerpos marcados, crímenes silenciados, violencia sexual contra las mujeres en el marco del conflicto armado. Recuperado de https://amnistiainternacional.org/publicaciones/14-colombia-cuerpos-marcados-crimenes-silenciados-violencia-sexual-contra-las-mujeres-en-el-marco-del-conflicto-armado.html

Butler, Jennifer (200o). Militarized Prostitution: The Untold Story (U.S.A.). En War's Dirty Secret (pp. 245-260), editado por Anne Llewellyn Barstow. Cleveland, OH: Pilgrim Press.

Butler, Judith (2007). Género en disputa. El feminismo y la subversión de la identidad. Buenos Aires: Paidós.

Castellanos, Juan Manuel (2011). Formas actuales de movilización armada. Manizales: Universidad de Caldas.

Centro Nacional de Memoria Histórica (2012). El placer: mujeres, coca y guerra en el bajo Putumayo. Bogotá: Taurus Pensamiento.

Centro Nacional de Memoria Histórica (2013). ¡Basta ya! Colombia, memorias de guerra y dignidad. Bogotá: CNMH/DPS.

Centro Nacional de Memoria Histórica (2015). Aniquilar la diferencia. Lesbianas, gays, bisexuales y transgeneristas en el marco del conflicto armado colombiano. Bogotá: CNMH/UARIV/ USAID/OIM.

Centro Nacional de Memoria Histórica (2017). La guerra inscrita en el cuerpo. Informe nacional de violencia sexual en el conflicto armado. Bogotá: CNMH.

Cifuentes, Rocío (2009). La investigación sobre género y conflicto armado. Eleuthera, 3, 127-164.

Comisión Nacional de Reparación y Reconciliación (2011). Mujeresy guerra: víctimasy resistentes en el Caribe Colombiano. Bogotá: Taurus Pensamiento.

Corporación Humanas (s.f.). Violencia sexual en contra de las mujeres en el contexto del conflicto armado colombiano. Colombia 2001-2009. Bogotá: Corporación Humanas. Recuperado de https://www.humanas.org.co/archivos/1oxfampdf2.pdf

Corte Constitucional de Colombia (2008). Auto 092 de 2008. Recuperado de http://www. corteconstitucional.gov.co/relatoria/autos/2008/ao92-o8.htm

Escuela de Estudios de Género (2015). Boletina anual \# 4. Prostitución, trabajadoras sexualesy justicia social. Bogotá: Universidad Nacional de Colombia.

Gallego, Gabriel (2011). Sexualidad, regulación y políticas públicas. En Sexualidade e política na América Latina (pp. 111-119), editado por Sonia Corrêa; Richard Parker. Recuperado de http://www.sxpolitics.org/wp-content/uploads/2011/o7/dialogo-la_total.pdf\#page=112

Gallego, Gabriel; Yáñez, Carlos; Rodríguez, Jorge; Sánchez, Carmenza; Giraldo, Sebastián (2018). Sobreviviendo a pesar de la limpieza, memorias de personas LBGT en el marco del 
conflicto armado en Caldas, 1985-2015. Manizales: Universidad de Caldas/Universidad Nacional de Colombia.

Hurtado Saa, Teodora (2015). La prostitución en Colombia: debates en torno al Proyecto de Ley 079 de 2013. En Boletina Anual \# 4. Prostitución, trabajadoras sexuales y justicia social (pp. 25-34). Bogotá: Universidad Nacional de Colombia.

Kumar, Krishna (2001). Women \& Civil War: Impact, Organizations and Action. London: Lynn Rienner Publishers.

Mbembe, Achille (2011). Necropolítica. Madrid: Melusina.

Moser, Caroline; Clark, Fiona (2001). Victims, Perpetrators or Actors? Gender, Armed Conflict and Political Violence. London: Zed Books.

Nieto, José Miguel (2008). A angústia dos corpos indóceis: prostituição e conflito armado na Colômbia contemporânea. Cadernos Pagu, 31, 365-397. http://dx.doi.org/10.159o/So10483332008000200016

Nieto, José Miguel (2013). Bajo el dintel del putiadero: Estado, prostitución y violencia en Colombia y Brasil. Cadernos Pagu, 41, 339-369. http://dx.doi.org/10.1590/So10483332013000200017

Nieto, José Miguel (2015). “Dios me la puso en el medio para mi remedio!”: esferas públicas y producción jurídica de la "prostitución" en la Colombia actual. Revista Colombiana de Antropología, 51(1), 109-135. https://doi.org/10.22380/2539472X29

Olujic, Maria B. (1998). Embodiment of Terror: Gendered Violence in Peacetime and Wartime in Croatia and Bosnia-Herzegovina. Medical Anthropology Quarterly, 12(1), 31-5o. https:// doi.org/10.1525/maq.1998.12.1.31

Orduz, Frank (2015). Victimización y violencia sexual en el conflicto armado en Colombia. Subjetividady Procesos Cognitivos, 19(2), 173-186. Recuperado de http://www.redalyc.org/ articulo.oa?id=339643529009.

Palacio, María Cristina; Cifuentes, Rocío (2005). El departamento de Caldas: su configuración como territorio de conflicto armado y desplazamiento forzado. Revista Trabajo Social, 7, 99-110.

Perea, Carlos Mario (2015). Limpieza social. Una violencia mal nombrada. Bogotá: CNMH.

Pinzón, Diana (2009). La violencia de género y la violencia sexual en el conflicto armado colombiano: indagando sobre sus manifestaciones. En Guerra y violencias en Colombia: herramientas e interpretaciones (pp. 353-393), editado por Jorge A. Restrepo; David Aponte. Bogotá: Pontificia Universidad Javeriana. 
Rubin, Gayle (1986). El tráfico de mujeres, notas sobre la "economía política” del sexo. Nueva Antropología, 8(30), 95-145.

Segato, Rita Laura (2002). Las estructuras elementales de la violencia. Buenos Aires: Prometeo.

Segato, Rita Laura (2013). Las nuevas formas de guerra y el cuerpo de las mujeres. Puebla: Pez en el Árbol.

Simons, Helen (2011). El estudio de caso: teoría y práctica. Madrid: Morata.

Sørensen, Birgitte (1998). 'Women and Post-conflict Reconstruction: Issues and Sources', Occasional Paper No 3. Ginebra: United Nations Research Institute for Social Development.

Stanley, Ruth (2007). Violencia sexualizada en tiempos de guerra: discursos hegemónicos y orden de género. Cuadernos de Antropología Social, 25, 7-27. https://doi.org/10.34096/cas. i 25.4376

Uribe, María Victoria (2004). Antropología de la inhumanidad. Un ensayo interpretativo sobre el terror en Colombia. Bogotá: Universidad del Rosario.

Uribe, María Victoria (2015). Hilando fino. Voces femeninas de la violencia. Bogotá: Universidad del Rosario.

Villa, Elvira (2010). Estudio antropológico en torno a la prostitución. Cuicuilco, 17(49), 157-179.

Wood, Elisabeth (2009). Armed Groups and Sexual Violence: When is Wartime Rape Rare? Politics \& Society, 37(1), 131-161. https://doi.org/10.1177/o032329208329755

Wood, Elizabeth (2015). Conflict Related Sexual Violence and the Policy Implications of Recent Research. International Review of the Red Cross, 96(894), 457-478. https://doi.org/10.1017/ S1816383115000077

Young, Iris Marion (2003). The Logic of Masculinist Protection: Reflections on the Current Security State. Journal of Women in Culture and Society, 29(1), 1-25. https://doi.org/10.1086/375708 